\title{
Sobre ensinar a ler: um olhar às múltiplas semioses e discursos implicados na construção dos sentidos
}

Luciana Maria Crestani*

Elisane Regina Cayser**

Karen Sartori***

\section{Resumo}

Para formar leitores plenos, é preciso ensinar a ler. Isso significa ensinar o que olhar nos textos, de modo a compreender sentidos relacionados às escolhas discursivas e enunciativas materializadas por meio de diferentes sistemas semióticos. Sob essa ótica, neste artigo, propomos a análise de dois gêneros textuais distintos - um verbal e outro sincrético - no intuito de observar os principais elementos semióticos implicados na construção dos sentidos desses textos, bem como as relações dialógicas que entre eles se estabelecem. Mais especificamente, procuramos explicitar, a partir dos elementos da materialidade textual (palavras e imagens), os temas veiculados pela constituição figurativa e as diferentes posições discursivas assumidas pelos narradores em relação ao assunto, evidenciando, assim, o diálogo entre os textos. Preceitos bakhtinianos e da semiótica discursiva ancoram o estudo ora proposto.

Palavras-chave: Leitura. Dialogismo. Semiótica Discursiva. Miniconto. História em Quadrinhos.

\section{Introdução}

A contemporaneidade, marcada pela difusão das tecnologias da informação e da comunicação, traz a campo uma nova variedade de textos. Se antigamente os únicos textos a que se tinha acesso em livros, revistas, jornais ou em outros suportes de leitura eram os exclusivamente verbais escritos, no formato impresso, hoje a realidade é outra. Somos expostos a textos intrinsecamente heterogêneos, constituídos de múltiplas semioses e veiculados em novos suportes de leitura

* Doutora em Letras (UPM-SP), mestre em Educação (UPF-RS). Professora no Curso de Letras e no Programa de Pós-Graduação em Letras da Universidade de Passo Fundo. E-mail: lucianacrestani@upf.br

** Doutoranda em Letras e professora no Curso de Letras da Universidade de Passo Fundo (UPF). E-mail: ecayser@upf.br

*** Graduada em Letras pela Universidade de Passo Fundo (UPF). E-mail: ksartori16@gmail.com

Data de submissão: dez. 2018 - Data de aceite: mar. 2019 http://dx.doi.org/10.5335/rdes.v15i1.8996 
e escrita, quer sejam mídias impressas ou audiovisuais, digitais ou não, de fácil e amplo acesso. Esses textos, caracterizados como multissemióticos, ou sincréticos - na terminologia da semiótica discursiva -, suscitam novos saberes para a construção de seus significados, exigindo do leitor outras práticas de compreensão e de produção.

A despeito disso, os índices de desempenho dos estudantes da educação básica constatados em instrumentos avaliativos do Ministério da Educação (MEC), como a prova Brasil e, principalmente, o Exame Nacional do Ensino Médio (Enem), têm revelado um histórico de dificuldades do alunado brasileiro no que concerne às habilidades de interpretação textual. Considerando que nesses exames muitas questões são constituídas por textos sincréticos e, principalmente, que textos dessa natureza são cada vez mais presentes nas práticas sociais, faz-se necessário desenvolver propostas de abordagem textual em que se explorem outras linguagens além da verbal, auxiliando os alunos-sujeitos na percepção de outros elementos semióticos implicados na construção de sentidos.

Além disso, o caráter dialógico do discurso (BAKHTIN, 2011) não pode ser negligenciado no ensino da leitura e da produção textual. Para que o aluno aprenda a inter-relacionar ideias, a perceber pontos de vista convergentes e divergentes sobre um assunto e a formar seu próprio posicionamento a respeito, 0 trabalho com o texto numa perspectiva dialógica é essencial.
Com base nessas considerações, propomos, neste artigo, a abordagem de dois textos constituídos por diferentes linguagens, um de natureza verbal e um de natureza sincrética, observando os principais elementos semióticos implicados na construção de sentidos e as relações dialógicas que entre eles se estabelecem. Mais especificamente, procuramos explicitar, a partir dos elementos da materialidade textual (palavras e imagens), os temas veiculados pela constituição figurativa e as diferentes posições discursivas assumidas pelos narradores em relação ao assunto, evidenciando, assim, as relações interdiscursivas que se estabelecem. Os textos selecionados são: o miniconto "Crônica familiar", de Eduardo Galeano, e uma história em quadrinhos (HQ) da Mafalda, do cartunista Quino.

Para empreender tal tarefa, inicialmente discorremos sobre o caráter dialógico dos enunciados, à luz de estudos de Bakhtin (2011) e de Fiorin (2006). Num segundo momento, com base, principalmente, em Fiorin (2009, 2016), Barros (2003, 2011) e Discini (2005), apresentamos preceitos da teoria semiótica discursiva que conduzem a análise da materialidade textual para, então, procedermos à abordagem dos textos.

\section{Sobre o diálogo entre discursos}

A interação humana ocorre, na maior parte das vezes, por meio da utilização da língua, na forma de enunciados, quer 
sejam eles orais ou escritos. Em cada esfera discursiva (familiar, religiosa, jurídica, artística, empresarial, científica etc.), são produzidos enunciados mais ou menos estáveis, os quais dão origem aos gêneros discursivos, ou gêneros do discurso (BAKHTIN, 2011). Materializados em forma de enunciados concretos e irrepetíveis, os gêneros expressam as condições específicas e as finalidades das esferas de ação humana (escola, trabalho, política, igreja, família, círculo de amigos, etc.) em que estão inseridos "não só por seu conteúdo (temático) e pelo estilo de linguagem [...] mas, acima de tudo, por sua construção composicional" (BAKHTIN, 2011, p. 261). Conteúdo temático, estilo e construção composicional são, então, os três elementos essenciais que possibilitam entender e reconhecer um enunciado, bem como o campo discursivo a que ele pertence.

Fiorin (2006), ao abordar os estudos bakhtinianos sobre gêneros, aponta que o conteúdo temático é relativamente previsível dentro de cada gênero. Por exemplo, cartas de amor versarão sobre relações amorosas, enquanto um livro de receitas versará sobre como preparar quitutes, etc. A construção composicional, afirma o autor, é a forma de organização e estruturação do texto. A receita, por exemplo, apresenta, em geral, o nome do prato a ser preparado, seguido da lista de ingredientes e do modo de preparo. Já o estilo, destaca Fiorin (2006), refere-se às formas linguísticas selecionadas para transmitir o sentido pretendido: engloba escolhas lexicais, sintáticas e de registro linguístico (formal/informal).

Além disso, os enunciados são tomados por Bakhtin (2011) como as "reais unidades" da comunicação, visto que "o discurso só pode existir de fato na forma de enunciações concretas de determinados falantes, sujeitos do discurso. $O$ discurso sempre está fundido em forma de enunciado pertencente a um determinado sujeito do discurso, $e$ fora dessa forma não pode existir" (BAKHTIN, 2011, p. 274, grifo nosso). Nesse contexto, o discurso é entendido como ideias, abstrações que circulam em um domínio discursivo e que apenas podem ser conhecidas pelos falantes ao serem enunciadas em forma de texto. Logo, temos um enunciado/texto ${ }^{1}$ quando um sujeito toma posse de um discurso circulante em determinada esfera e o enuncia a seu modo, a partir de suas concepções e de seu estilo.

Para Bakhtin (2011), o enunciado apresenta como características principais: constituir um todo de sentido; ter responsividade (possibilidade de dar e esperar uma resposta); ter conclusibilidade (demarcada pela alternância dos sujeitos falantes) e ter caráter dialógico. A natureza dialógica, traço ao qual nos dedicamos amiúde neste trabalho, diz respeito às relações de sentido que os enunciados estabelecem com outros discursos/textos na arena discursiva, ao que já foi e ao que ainda será dito sobre dado assunto. Todo enunciado dialoga, pois, com outros enunciados anteriores 
a ele ou que lhe serão posteriores, em um processo responsivo constante de reelaboração e transformação do que foi ou será dito/escrito/representado. Sobre isso, o teórico russo defende que

[...] cada enunciado isolado é um elo na cadeia da comunicação discursiva. [...] $\mathrm{O}$ objeto do discurso do falante, seja esse objeto qual for, não se torna pela primeira vez objeto do discurso em um dado enunciado, e um dado falante não é o primeiro a falar sobre ele. O objeto, por assim dizer, já está ressalvado, contestado, elucidado e avaliado de diferentes modos; nele se cruzam, convergem e divergem diferentes pontos de vista, visões de mundo, correntes (BAKHTIN, 2011, p. 299).

Assim, os enunciados nada mais são do que réplicas que evocam outras e novas réplicas - eis o caráter responsivo dos enunciados, que implica uma compreensão responsiva ativa do que foi dito e um juízo de valor, o qual se forma com base em discursos já internalizados. Por isso, os estudos bakhtinianos, ao diferenciarem unidades da língua (palavras e orações) de unidades da comunicação (enunciados), apontam que aquelas apresentam significado, ao passo que estas possuem sentido: "[...] isto é, um sentido pleno, relacionado com o valor - com a verdade, a beleza, etc. - e que requer uma compreensão responsiva que inclui em si o juízo de valor" (BAKHTIN, 2011, p. 332). Logo, a compreensão responsiva ativa pressupõe sempre um juízo de valor atrelado ao conteúdo.

Ainda em relação ao enunciado e sua natureza dialógica, Bakhtin (2011, p. 331) salienta: "dois enunciados dis- tantes um do outro, tanto no tempo quanto no espaço, que nada sabem um sobre o outro, no confronto dos sentidos revelam relações dialógicas se entre eles há ao menos alguma convergência de sentidos (ainda que seja uma identidade particular do tema, do ponto de vista, etc.)". Portanto, há dialogismo se há relação semântica entre os enunciados, independentemente da relação estabelecida (de complementação, de recusa, de aceitação, de divergência etc.). Fiorin (2006) explica que essa forma de dialogismo constitutivo, intrínseco à natureza dos enunciados, é também chamado de interdiscursividade ${ }^{2}$.

É importante destacar, ainda, que todo e qualquer enunciado só se realiza quando corporificado na forma de algum gênero textual. Nesse sentido, texto é aqui entendido como a materialização de um discurso em forma de um gênero textual. O discurso, segundo Fiorin, é da ordem do sentido, da imanência, e o texto, da materialidade, "que advém do fato de ser um conjunto de signos" (2006, p. 52). A propósito, Bakhtin afirma que o texto é a única forma de se ter acesso aos discursos: "onde não há texto, não há objeto de pesquisa e pensamento" (BAKHTIN, 2011, p. 329). Logo, texto e enunciado são tomados como sinônimos neste trabalho, pois o enunciado, obrigatoriamente, será materializado na forma de um gênero textual, que pode ser expresso de forma pictórica, verbal, sincrética etc. 
A seguir, abordamos a concepção de texto à luz da semiótica e os preceitos da teoria que, juntamente com os estudos de Bakhtin, sustentam a análise empreendida.

\section{Preceitos da semiótica discursiva: a construção de sentidos nos textos}

A semiótica discursiva - também conhecida como teoria semiótica do texto e como semiótica greimasiana -, cujo precursor é Algirdas Julien Greimas, é uma teoria do texto e do discurso que tem por objetivo compreender e explicar como se constroem os sentidos textuais/ discursivos, ou, nas palavras de Greimas e Courtés, "explicitar, sob a forma de construção conceitual, as condições da apreensão e da produção do sentido" (2008, p. 255). Para isso, leva em conta tanto elementos internos do texto quanto elementos exteriores a ele, relacionados à situação de enunciação, como as relações dialógicas, por exemplo.

Nesse sentido, é relevante mais uma vez deixar clara a relação, na perspectiva da semiótica, entre texto e discurso. Fiorin (2016) explica que um texto nasce da união de um plano de conteúdo (da ordem do discurso) com um plano de expressão (da ordem da materialidade semiótica). Isso significa que um mesmo discurso pode ser "materializado" por sistemas sígnicos diferentes. Por exemplo, o discurso da miséria e do sofrimento por ela infligido pode ser expresso em forma de um livro, de um filme ou mesmo de uma fotografia - a exemplo dos registros de Sebastião Salgado ${ }^{3}$. Cada uma dessas manifestações se configura como um texto que comporta tal discurso.

O discurso é social, é de todos e, ao mesmo tempo, de ninguém. Já o texto, enquanto materialização de um discurso, implica escolhas enunciativas atreladas à situação de enunciação que atribuem a ele (ao texto) um caráter de individualidade, de autoria, como explica Bakhtin (2011, p. 310) ao dizer que "cada texto (como enunciado) é algo individual, único e singular, e nisso reside o seu sentido (sua intenção em prol da qual foi criado)". Assim, não há texto sem discurso, nem discurso sem textualização. São os textos - mais propriamente os gêneros textuais - que concretizam discursos e possibilitam sua difusão social.

Os gêneros textuais podem ser expressos por linguagem verbal, não verbal ou sincrética, sendo estes últimos constituídos por mais de uma forma de expressão, a exemplo dos filmes, das HQs, das publicidades e tantos outros em que se mesclam elementos da expressão verbal (palavras) com elementos da expressão visual (imagens) ${ }^{4}$. Conforme Fiorin, o sincretismo de linguagens constitui um mecanismo de enunciação em que um mesmo enunciador recorre "a uma pluralidade de linguagens de manifestação para construir o texto sincrético" (2009, p. 39).

Nesse sentido, quando se aborda um texto sincrético, é preciso relacionar as 
diferentes linguagens, buscando tanto nos elementos verbais como nos não verbais as marcas - ou "pistas do mapa da mina", no dizer de Koch (2003) espalhadas na superfície textual pelo enunciador com vistas à construção do sentido pretendido, ou seja, do ponto de vista ali expresso.

Para explicar o processo de construção e apreensão do sentido de um texto, a semiótica concebe um percurso gerativo de sentido, que compreende três níveis de análise: fundamental, narrativo e discursivo. O percurso gerativo simula tanto o caminho empreendido na produção de um texto quanto na sua recepção, propondo que o produtor do texto parte do nível fundamental - o mais abstrato e simplificado - e, num processo de enriquecimento semântico, segue na elaboração do nível narrativo e, por fim, do discursivo, em que o discurso recebe investimentos temáticos e figurativos que o tornam mais concreto. Já o leitor/ receptor faz o caminho inverso, partindo do nível discursivo, o mais concreto, e, num processo de abstração, vai em direção do narrativo e do fundamental. $\mathrm{Na}$ abordagem dos textos selecionados neste artigo, faremos o caminho do leitor: observaremos as marcas ou pistas espalhadas no nível discursivo para, a partir delas, compreender os termos fundamentais sobre o qual o discurso se erige ${ }^{5}$.

O nível fundamental, ou profundo, é o mais abstrato de todos. Ele é formado por dois termos opostos (A versus B) de uma mesma categoria semântica, como vida versus morte, amor versus ódio, cidade versus campo etc. Cada um desses termos recebe uma qualificação semântica: eufórica (positiva) ou disfórica (negativa). A qualificação semântica diz respeito ao "valor" atribuído pelo enunciador a esses termos no texto. Por exemplo, nos textos construídos sobre a oposição vida versus morte, há textos em que a morte é qualificada de forma negativa, enquanto a vida é valorada euforicamente. Já em outros, a morte pode aparecer com qualificação eufórica - como uma forma de cessar a dor e aliviar o sofrimento, por exemplo enquanto a vida será disfórica.

O nível narrativo corresponde a um simulacro das ações dos homens sobre o mundo e sobre os outros homens. É neste nível que os termos abstratos do nível fundamental se tornam valores (objeto-valor) e são buscados por sujeitos, os quais operam, para tanto, transformações de estado. Por exemplo, um texto em que a vida seja tomada como eufórica poderia relatar a trajetória de um sujeito que luta para mantê-la. Esse nível, portanto, um pouco menos abstrato do que o fundamental, constitui-se de uma organização narrativa em que se delineiam os jogos de interesses na busca por objetos-valores, os sujeitos ${ }^{6}$ envolvidos e as ações e transformações decorrentes dessa busca.

O nível discursivo, por seu turno, é o mais concreto de todos, uma vez que nele se materializam as escolhas 
enunciativas feitas para discursivizar/ enunciar o discurso. Barros explica que "pela própria definição do percurso gerativo, as estruturas discursivas são mais específicas, mas também mais complexas e 'enriquecidas' semanticamente, que as estruturas narrativas e as fundamentais" (2003, p. 53). É neste nível que se estabelecem os temas e as figuras, fazendo com que os elementos mais abstratos do nível narrativo ganhem "forma". Sobre os conceitos de tema e de figura, temos que:

A oposição entre tema e figura remete, em princípio, à oposição abstrato/concreto. [...] A figura é o termo que remete a algo existente no mundo natural: árvore, vagalume, sol, correr, brincar, vermelho, quente, etc. Assim, a figura é todo conteúdo de qualquer língua natural ou de qualquer sistema de representação que tem um correspondente perceptível no mundo natural. [...] Tema é um investimento semântico de natureza puramente conceptual, que não remete ao mundo natural. Temas são categorias que organizam, categorizam, ordenam os elementos do mundo natural: elegância, vergonha, raciocinar, calculista, orgulhoso, etc. (FIORIN, 2016, p. 91).

Discini cita o tema da dilapidação do patrimônio público para explicar como ele pode vir figurativizado nos textos, dizendo que tal tema "pode concretizar-se num feixe de figuras como: superfaturar o preço de compra de material para construção de prédios públicos; deixar de pagar impostos; fazer lavagem de dinheiro em contas bancárias abertas em países estrangeiros [...]”. (2005, pp. 264-265).

Voltemos ao tema da luta pela vida, já citado na explicação dos níveis ante- riores, para melhor compreender como os elementos dos níveis fundamental e narrativo são concretizados em figuras no nível discursivo. Num texto que tematiza a luta pela vida, o nível fundamental se estrutura com base nos termos vida (eufórico) vs. morte (disfórico). O nível narrativo poderá apresentar a trajetória de um sujeito que busca manter ou recuperar a vida/saúde e que, para tanto, efetua ações em prol do que deseja. No nível discursivo, esse sujeito poderá ser representado, figurativamente, por um homem, por uma criança, por um animal etc. $\mathrm{O}$ objeto-valor (vida/saúde) poderá vir figurativizado como a cura da doença, a estabilização desta ou a redução dos sintomas, por exemplo. As transformações e as ações operadas pelo sujeito na busca pelo objeto-valor também ganham concretude: a conquista do dinheiro necessário para a realização do tratamento poderia advir da venda de uma casa ou de uma doação social, por exemplo. Também o tempo e o espaço em que a narrativa se desenrola vêm expressos neste nível, assim como todas as outras escolhas/estratégias enunciativas utilizadas para persuadir o leitor (narração em $1^{\text {a }}$ ou $3^{\text {a }}$ pessoa, delegação de vozes em discurso direto, figuras de linguagem, variantes linguísticas, entre tantas outras).

Nesse sentido, os estudos da enunciação à luz da semiótica se voltam à análise do nível discursivo, observando escolhas discursivas (temas e posições sobre eles) e enunciativas (estratégias 
do dizer) que se materializam no texto e produzem sentidos. São essas as "pistas" que, espalhadas no texto, precisam ser observadas para a apreensão do sentido pretendido ${ }^{7}$. Não é demais lembrar que essas estratégias estão relacionadas ao nível profundo do texto, onde se definem as valorizações axiológicas.

As estratégias enunciativas são distintas, dependendo das características dos gêneros textuais. Por exemplo, num texto verbal, como um romance, o sujeito será figurativizado por meio de termos descritivos, os quais darão informações sobre seu nome, sua idade, características físicas e psicológicas, profissão, espaço em que se situa etc. Já num texto cujo plano de expressão é pictórico - como as HQs - esse conteúdo será materializado por meio de imagens. Chamamos personagens, ou atores, aos sujeitos figurativizados inscritos no texto ${ }^{8}$.

Por fim, cabe ainda uma breve menção à problemática das instâncias enunciativas ${ }^{9}$. Num texto, há três instâncias enunciativas que, grosso modo, podem ser assim definidas: a do enunciador/ enunciatário, sendo o enunciador uma instância pressuposta pela própria existência do texto; a do narrador/narratário, sendo o narrador delegado pelo enunciador e responsável pelo relato dos acontecimentos; a do interlocutor/interlocutário, sendo o interlocutor o ator/personagem a quem o narrador delega voz em discurso direto. No caso dos textos sob análise na sequência, temos a presença do narrador e dos interlocutores, sendo que o enunciador não aparece no texto, pois é uma instância pressuposta.

Vamos, então, à abordagem dos textos.

\section{Análise dos textos}

Não é recente a discussão travada em diferentes espaços sociais, sobretudo no contexto escolar e familiar, sobre o tempo que as crianças passam em frente à televisão e a influência dos programas televisivos sobre elas. Nesse sentido, escritores, pensadores, produtores de arte e literatura já trouxeram a campo, ao longo dos anos, textos diversos sobre o tema: muitos defendem a ideia de que os programas televisivos, em sua maioria, são inadequados às crianças, enquanto tantos outros concebem uma visão positiva em relação à atuação da TV e de suas programações sobre o universo infantil. Esse confronto entre favoráveis e/ou contrários põe em evidência o dialogismo existente entre os discursos que circulam sobre o tema, ao passo que esse diálogo também se manifesta nos dois textos em foco neste trabalho.

As perguntas que norteiam nossa análise são: o que os textos dizem? Como dizem o que dizem, ou seja, que elementos da materialidade textual nos possibilitam depreender os sentidos discursivos? Que tipo de relação dialógica se estabelece entre eles? Para respondê-las, analisamos primeiramente o miniconto, depois a HQ e, por fim, relacionamos os dois, apontando as diferentes perspectivas discursivas manifestas sobre o tema. 


\section{Análise do miniconto "Crônica Familiar"}

O primeiro texto é o miniconto "Crônica familiar", do autor uruguaio Eduardo Galeano:

Texto 1 - Miniconto

\section{Crônica familiar}

Em Assunção do Paraguai, morreu a tia mais querida de Nicolas Escobar. Morreu serenamente, em casa, enquanto dormia. Quando soube que perdera a tia, Nicolas tinha seis anos e milhares de horas de televisão. E perguntou:

- Quem a matou?

Fonte: Eduardo Galeano (1999).

O gênero miniconto caracteriza-se, basicamente, por sua brevidade, já que consiste em uma espécie de conto muito pequeno. Santos (2015) afirma que, apesar de ser extremamente conciso, o texto apresenta narratividade e intensidade, podendo ser chamado de microconto, nanoconto, microficção, minificção, microrrelato e conto brevíssimo. A característica principal do gênero é, com $o$ mínimo de palavras possíveis, retratar todo um contexto e uma ação em torno do pouco revelado pelas palavras. No miniconto, mais importante que mostrar é sugerir, deixando ao leitor a tarefa de preencher as elipses narrativas e entender o que está por trás do texto. Sobre isso, pontuam Rodrigues, Souza e Souza (2013) que esse gênero literário combina duas histórias, uma visível e uma oculta, cabendo ao leitor apreender a que está subentendida, pois é esta que, de fato, importa para a compreensão dos sentidos textuais. Por isso, segundo as autoras, ler e compreender um texto do gênero miniconto implica um tipo de leitor mais proficiente, perspicaz.

No nível discursivo do miniconto "Crônica familiar" há elementos essenciais que precisam ser considerados pelo leitor durante $o$ ato de leitura, pois remetem diretamente ao sentido do texto. Também há de se enfatizar que esse texto vem manifesto pela linguagem verbal escrita, logo as marcas vêm materializadas nas escolhas linguísticas/vocabulares. Primeiramente, instaura-se no texto um narrador em $3^{\text {a }}$ pessoa, que situa a narrativa num espaço - "em Assunção do Paraguai" - e discorre sobre um fato pontual: a reação de um sujeito ao saber da morte de um parente - a tia. Esse sujeito que sofre a perda aparece figurativizado como Nicolas Escobar, com " 6 anos e milhares de horas de televisão". A figura "seis anos" remete o leitor à compreensão de que Nicolas é uma criança, e a expressão "milhares de horas de televisão" figurativiza o tema da exposição exagerada das crianças aos programas televisivos. Aliás, tal expressão é uma hipérbole, um recurso semântico utilizado para denotar o exagero de tempo que as crianças (representadas por Nicolas) passam em frente à TV. Porém, até aqui, ainda não se pode dizer se essa exposição das crianças ao veículo de massa será investido de valoração positiva ou negativa, o que ficará subentendido adiante. 
Ao receber a notícia da morte da "tia mais querida", o menino - instaurado como interlocutor em discurso direto pergunta: “Quem a matou?". Essa pergunta traz consigo o tema da violência urbana, comumente presente em programas televisivos. $\mathrm{O}$ fato de a pergunta ter sido feita por um menino de seis anos remete à assimilação, por parte das crianças, da violência veiculada pelos programas televisivos, tanto é que o menino sequer consegue cogitar a ideia de uma morte natural, como realmente foi a da tia, expressa no trecho "Morreu serenamente, em casa, enquanto dormia". Aliás, esse último trecho é essencial para se compreender que efetivamente a tia não fora assassinada, como pensou $\mathrm{Ni}$ colas em decorrência das suas "milhares de horas de televisão". A pergunta feita pelo menino, então, é também elemento primordial na construção do tema desse texto: não se trata apenas de uma exposição exagerada das crianças à televisão, mas, sim, de uma exposição exagerada a cenas de violência capazes de alienar, de condicionar a mente das crianças.

Constrói-se, então, no texto "Crônica familiar”, uma posição crítica sobre o tema, enfatizando a influência negativa dos programas televisivos sobre as crianças, que são de tal forma expostas a cenas de violência que acabam concebendo a realidade por meio dessa lente. Isso fica evidente por sabermos que uma criança tão pequena não possui a concepção de morte por assassinato, a não ser que tenha vivenciado de forma próxima tal realidade ou tenha sido exposta a conteúdos dessa ordem em algum lugar. Nicolas Escobar presenciou isso na televisão.

Chama a atenção, ainda, o título "Crônica familiar". O termo "crônica" é utilizado para nomear um gênero textual que versa sobre acontecimentos cotidianos, comuns. Assim, a expressão "Crônica familiar" traz consigo a ideia de que o fato relatado é comum, costumeiro na maioria das famílias: as crianças passam horas diante da TV, expostas a programas nada educativos. Nesse texto, então, podemos dizer que se constrói um discurso disfórico em relação aos programas televisivos, defendendo que eles contribuem apenas para a introjeção da violência, em vez de estimular o crescimento cultural - posição defendida por outros discursos sobre o tema.

No nível fundamental deste texto, confrontam-se os termos atrofia versus estímulo. A atrofia vem representada pela postura adotada pelo menino de incorporação dos conteúdos violentos dos programas exibidos pela televisão, os quais restringem as concepções das crianças às perspectivas por eles apresentados. Já o estímulo estaria relacionado ao potencial positivo desse veículo como promotor de conhecimentos, de aprendizados culturais importantes para o desenvolvimento da criança. A atrofia, neste texto, é valorada negativamente, enquanto que o estímulo é valorado positivamente. 
A esse respeito, é preciso esclarecer que os termos opostos sobre os quais o discurso se estrutura nem sempre aparecem explícitos na superfície textual. É este o caso do texto sob análise, em que somente aparece, explicitamente, o tema da atrofia mental projetada pela TV. O termo contrário, nesse sentido, precisa ser recuperado pelo leitor. Afinal, só se defende uma posição discursiva porque há o seu oposto, ou seja, este texto somente defende que a TV promove a alienação, a atrofia porque outros defendem que ela promove o estímulo à reflexão acerca do mundo circundante.

Dado o fato de que nenhuma escolha linguística é aleatória, sobretudo em textos de natureza estética, como é o caso dos minicontos, é preciso atentar para os recursos empregados. Isso vai ao encontro do que salientam Fiorin (2016) e Koch (2003): faz-se necessário, no contexto da educação escolar, ensinar a ler, a perceber no texto elementos importantes na construção de sentidos.

\section{Análise de HQ da Mafalda}

O texto a ser analisado na sequência é uma HQ da Mafalda, do cartunista argentino Quino:
Texto $2-\mathrm{HQ}$ Mafalda

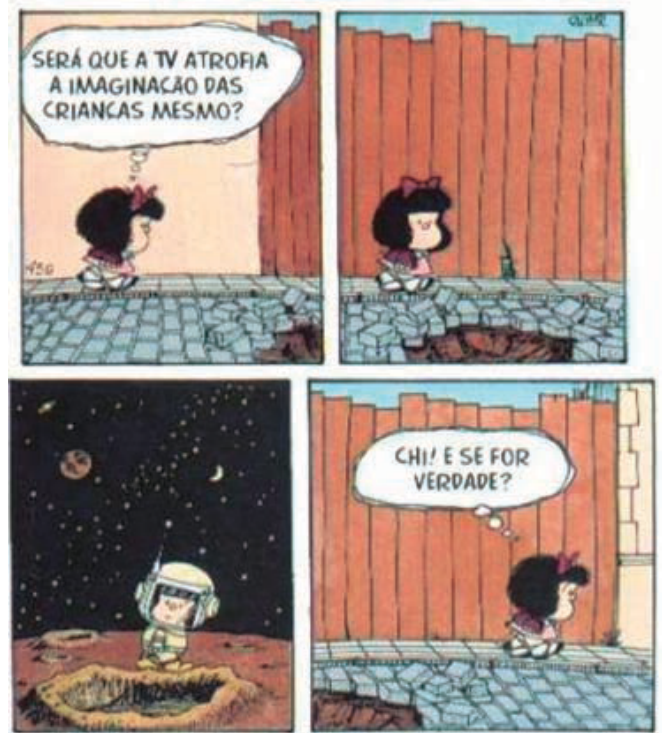

Fonte: Quino (2010).

Teixeira, Faria e Souza definem as histórias em quadrinhos (HQs) como

[...] textos sincréticos do tipo verbo-visual, em que uma sequência de quadros com desenho e, em geral, texto verbal apresentado em balões, desenvolve uma narrativa. Podem concretizar-se em diferentes gêneros, como a tira de humor, a história de aventuras, os quadrinhos de terror etc. (TEIXEIRA, FARIA, SOUZA, 2014, p. 324)

Nesses textos, "a expressão verbal e a visual, longe de se manterem discretas, separadas, juntam-se", sendo que o visual muitas vezes prevalece sobre o verbal na construção dos sentidos (DISCINI, 2005, p. 276). Segundo a autora, são características das HQs: a instalação de interlocutores/personagens no enunciado; o uso de discurso direto para veicular falas ou pensamentos; os balões de fala/pensamento; a incorporação dos 
quadrinhos para representar transformações/congelamento de cenas; o recurso de closes, com efeito de ênfase; o uso da perspectiva, para orientação do olhar; "tudo, aliás, marcado pela densidade icônica das figuras. HQs constituem textos predominantemente figurativos" (DISCINI, 2005, p. 277). Nas HQs, portanto, figuras e temas são veiculados por meio de elementos de diferentes semioses, que precisam ser percebidos e relacionados para a adequada construção dos sentidos.

$\mathrm{Na}$ HQ em análise, diferentemente do miniconto, não se instaura no texto um narrador que conta de forma verbal o que se passa - descrevendo os personagens, o espaço e narrando os fatos -, mas sim um narrador que organiza e conta a narrativa por meio de várias semioses, que, articuladas entre si, conduzem a história. Nesse sentido, se apenas olharmos a linguagem verbal que, em forma de discurso direto, representa os pensamentos da personagem/interlocutor Mafalda no $1 \square$ e $4 \square$ quadrinhos, não conseguiremos compreender o texto. Do mesmo modo, se apenas olharmos as imagens, sem ler o pensamento da personagem no $1 \square$ balão - "Será que a TV atrofia a imaginação das crianças mesmo?" - a compreensão do texto também será prejudicada.

Quanto aos elementos figurativos que remetem aos temas subjacentes e à posição do narrador em relação ao tema, é possível tecer as seguintes considerações: no primeiro quadrinho, instauram-se $o$ ator (Mafalda) e o espaço (rua), figu- rativizados de forma icônica. $\mathrm{Na} \mathrm{HQ}$ não há elementos verbais indicando quantos anos tem a criança, ao contrário do que acontece no miniconto. Percebemos, no entanto, que se trata de uma criança por conta da imagem da personagem/ator. Também o espaço em que a menina se encontra (rua) e o que está fazendo nele (caminhando) vêm figurativizados pela expressão visual. Nesse mesmo quadro, a menina se pergunta, em pensamento (representado pelas bolinhas que introduzem o texto do balão): "Será que a TV atrofia a imaginação das crianças mesmo?". Essa fala da menina remete diretamente ao tema do texto: a influência dos programas televisivos sobre a imaginação das crianças.

Se a pergunta não tivesse sido feita, não seria possível dizer que o tema é esse, podendo ser, em vez disso, a imaginação infantil. Mas a pergunta é sobre o papel da televisão em relação à imaginação das crianças, então a figura da TV aqui é essencial e não pode ser negligenciada na apreensão do tema. A palavra "atrofia", por sua vez, atribui à TV uma conotação negativa, remetendo ao tema/discurso da influência negativa da TV sobre as crianças. A expressão "será mesmo" indica a dúvida da garota sobre tal posição discursiva e, ao mesmo tempo, evidencia o dialogismo: a expressão mostra que a menina ouviu ou leu isso anteriormente em algum lugar (em outros textos/discursos) e faz, agora, sua própria reflexão -buscando uma resposta (convergente ou divergente) em rela- 
ção ao discurso ouvido/lido. Eis o caráter dialógico e responsivo dos enunciados, de que fala Bakhtin (2011).

Nos dois quadros seguintes (segundo e terceiro), Mafalda (uma criança) se depara com um buraco na rua e se imagina, provavelmente por influência dos programas a que assiste na TV, observando uma cratera na superfície de outro planeta, como uma astronauta. Nesses dois quadros, então, reitera-se de forma imagética o tema expresso de forma verbal na pergunta do primeiro quadro. No entanto, esses dois quadros dizem mais que isso: deles se pode depreender a posição do narrador em relação ao tema. Ao figurativizar a menina Mafalda vestida como uma astronauta observando uma cratera sobre a superfície de um outro planeta, o texto tematiza a influência positiva dos programas televisivos sobre a imaginação das crianças, uma vez que o conhecimento acerca da exploração de outros planetas (figurativizado pelas roupas de astronauta, pela superfície redonda com crateras, corpos celestiais ao fundo, céu escuro, etc.) está, neste texto, associado àquilo que se vê na TV. Não seria possível dizer que a imagem está relacionada ao que menina aprende nos livros ou na escola, por exemplo, porque não há no texto nenhuma marca enunciativa/discursiva que remeta a essa possibilidade de leitura. É sobre a influência da TV que o texto versa, como fica explícito na pergunta do primeiro quadro. Se essa influência vem figurativizada numa imagem positiva, que traz consigo a ideia de aquisição de conhecimentos e estímulo à imaginação por meio dos programas veiculados na TV, configura-se nesse texto um discurso favorável aos programas televisivos.

Nesse sentido, muito embora no último quadrinho seja figurativizada uma Mafalda ainda intrigada com o tema, em dúvida sobre o fato de a TV atrofiar ou não a imaginação das crianças (perceba-se a postura da menina, idêntica à do quadro 1 , e o balão de pensamento em que se lê "Chi! E se for verdade?"), o terceiro quadro dissipa tal dúvida: a reposta é não, a TV não atrofia a imaginação das crianças, ao contrário, ela a estimula. Tem-se, pois, um caso em que a dúvida é afirmada no enunciado, mas negada na enunciação.

O nível fundamental desse texto, a exemplo do miniconto, também pode ser compreendido como uma oposição entre os termos atrofia versus estímulo, sendo que aqui a TV aparece como instrumento de incentivo à criatividade e ao conhecimento, de estímulo sadio à imaginação, sendo valorada de forma positiva, ao contrário do texto anterior, em que os programas televisivos recebem uma valoração negativa por condicionarem a mente infantil aos conteúdos violentos por eles veiculados. 


\section{Diálogo entre miniconto e HQ: as diferentes posições discursivas}

$\mathrm{O}$ tema em foco tanto na $\mathrm{HQ}$ quanto no miniconto é o mesmo: a influência dos programas televisivos sobre as crianças. Sendo assim, esses dois textos estabelecem entre si uma relação dialógica, interdiscursiva. Como já dito, o dialogismo existe sempre que há algum elo entre os textos, sendo que reconstruir o diálogo entre textos "é identificar convergências ou divergências de pontos de vista entre um texto e outro" (DISCINI, 2005, p. 281). $\mathrm{O}$ miniconto e a $\mathrm{HQ}$ abordam o mesmo tema, porém com perspectivas divergentes, ou seja, manifestando posições discursivas diferentes, contrárias entre si.

O primeiro texto (miniconto) apresenta a TV como um instrumento de alienação, de atrofia mental das crianças. Como sabemos, esse discurso é muito comum no meio social, reportando os desenhos animados, os jogos de videogame e os noticiários televisivos como elementos de manipulação mental das crianças que acabam por levá-las a comportamentos estereotipados.

O segundo texto, por sua vez, projeta a ideia de que a televisão atua positivamente, estimulando a imaginação das crianças. Esse discurso se coaduna com outros que também defendem esse veículo como fonte de estímulo intelectual, como um instrumento que pode contribuir para o desenvolvimento da criatividade das crianças.

Os dois textos abordados, portanto, dialogam entre si, veiculando, como já dito, posições discursivas antagônicas sobre o mesmo tema.

\section{A título de conclusão}

Para finalizar, reiteramos, com Fiorin (2016), a concepção de que interpretar um texto não é uma questão de sensibilidade, mas de saber o que olhar nele para compreender os sentidos. Segundo o autor, é urgente que nas aulas de língua materna voltemos o foco para o ensino da interpretação e da produção de textos, ajudando o aluno a perceber a "gramática" de estruturação do discurso, entendida esta gramática como as escolhas discursivas e enunciativas relacionadas à construção de sentidos nos textos.

Nessa mesma perspectiva, cremos ser essencial, cada vez mais, o trabalho de análise de textos compostos por diferentes semioses. Foi nesse sentido que buscamos empreender o presente trabalho. Tecendo o caminho do leitor na interpretação dos dois textos em foco, buscamos explicitar o que olhamos na superfície de cada texto - e como olhamos - para construir os sentidos. $\mathrm{Ou}$ seja: procuramos mostrar como figuras representam temas subjacentes e denotam posições discursivas; procuramos, também, explicitar como se estabelece a relação dialógica entre os textos. 
Dito isso, é preciso enfatizar a importância da existência de bases teóricas que sustentem a análise e sirvam como apoio para professores e alunos na abordagem textual. Nesse viés, a semiótica discursiva e os estudos bakhtinianos sobre dialogismo se apresentam como bons suportes - logicamente, não os únicos - para conduzirem o trabalho.

Importa, pois, expandir horizontes de leitura, ajudando o aluno a perceber que os textos/discursos estão em constante diálogo e que as estratégias ou marcas enunciativas não são aleatórias, mas escolhas que produzem sentidos, apontando para certas possibilidades interpretativas e tolhendo outras.

On teaching to read: an outlook on the multiple semioses and speeches involved in the construction of meanings

\section{Abstract}

In order to form full readers, teaching to read is required. This means teaching what to look in texts so to understand the meanings related to the discursive and enunciative choices materialized through different semiotic systems. From this outlook, this study proposes the analysis of two distinct text genres (verbal and syncretic) in order to observe the main semiotic elements involved in the construction of meanings of such texts, as well as the dialogic relationships established between them. More specifically, we attempted to make explicit, from the elements of textual materiality (words and images), the topics served by the figurative constitution and the different discursive positions taken on by the narrators regarding the subject, thus evidencing the dialogue between the texts. Bakhtinian and discursive semiotic precepts supported the study hereby proposed.

Keywords: Reading. Dialogism. Discursive semiotics. Mini-story. Comics.

\section{Notas}

1 Como explicitamos no final desta seção, enunciado e texto são aqui tomados como sinônimos.

2 No presente artigo, utilizam-se as expressões relações dialógicas ou relações interdiscursivas para referir ao mesmo fenômeno.

3 Vejam-se as imagens da exposição de Sebastião Salgado "A fome em preto e branco", disponível no site: http://obviousmag.org/ archives/2010/08/a_fome_em_preto_e_branco_-_sebastiao_salgado.html

4 As imagens implicam sistemas semióticos de diferentes ordens, como cores, traços, gestualidade, símbolos etc. Cada um desses sistemas, no entanto, está serviço da construção do arranjo imagético como um todo.

5 Neste estudo, apresentamos de forma bem resumida os níveis de análise, priorizando aspectos dos níveis fundamental e discursivo que embasam a análise ora empreendida. Para um estudo básico dos três níveis do percurso gerativo do sentido e dos elementos neles implicados, recomendamos as obras Elementos de análise do discurso, de José Luiz Fiorin (2016), e Teoria semiótica do texto, de Diana Barros (2011).

6 "Sujeito e objeto são papéis narrativos que podem ser representados num nível mais superficial por coisas, pessoas ou animais" (FIORIN, 2016, p. 29).

7 Entendemos que a construção do sentido não depende apenas do enunciador, mas também do leitor/enunciatário, o qual apreende o sentido do texto a partir de suas experiências. Por outro lado, é preciso considerar que qualquer texto nasce de uma vontade discursiva do falante e 
que essa vontade discursiva, ao ser enunciada, vem permeada de marcas que indicam como esse discurso deverá ser lido (como uma crítica, um elogio, uma ironia etc.).

8 Por conta dos textos objeto de análise neste estudo, priorizamos, nesta exposição, aspectos relacionados ao texto narrativo. No entanto, como explicam Teixeira, Faria e Souza (2014, p. 317), a semiótica define-se como uma teoria geral do texto e da significação "que considera a articulação entre um plano do conteúdo e um plano da expressão e [desenvolve] categorias gerais de análise capazes de, por um lado, contemplar a totalidade dos textos, manifestados em qualquer materialidade e, por outro lado, definir as estratégias enunciativas particulares dos textos concretos".

9 As instâncias enunciativas são concebidas sempre em pares - enunciador-enunciatário, narrador-narratário, interlocutor-intelocutário. Isso porque a semiótica entende que o sujeito da enunciação é constituído pelo eu-tu, já que o $t u$ a quem se dirige o discurso interfere em todas as escolhas enunciativas do eu.

\section{Referências}

BAKHTIN, Mikhail. Estética da criação verbal. 6. ed. São Paulo: WMF Martins Fontes, 2011.

BARROS, Diana Luz Pessoa. Estudos do discurso. In: FIORIN, José Luiz (Org.). Introdução à Linguística II: princípios de análise. São Paulo: Contexto, 2003.

. Teoria semiótica do texto. São Paulo. 5.ed. São Paulo: Ática, 2011.

DISCINI, Norma. HQ e poema: diálogo entre textos. In: LOPES, Ivã Carlos; HERNANDES, Nilton. Semiótica: objetos e práticas. São Paulo: Contexto, 2005, pp. 261-283.

FIORIN, José Luiz. Introdução ao pensamento de Bakhtin. São Paulo: Ática, 2006.

. Por uma definição das linguagens sincréticas. In: OLIVEIRA, Ana Cláudia de; TEIXEIRA, Lucia. Linguagens na comunicação: desenvolvimentos de semiótica sincrética. São Paulo: Estação das Letras e Cores, 2009. p. 15-40.

. Elementos de análise do discurso. 15. ed. São Paulo: Contexto, 2016.

GALEANO, Eduardo. De pernas pro ar: a escola do mundo ao avesso. Porto Alegre: LPM, 1999.

GREIMAS, Algirdas Julien; COURTÉS, Joseph. Dicionário de semiótica. Contexto: São Paulo, 2008.

$\mathrm{KOCH}$, Ingedore. Linguística textual e ensino de português. In: TOLDO, Cláudia Stumpf. Questões de linguística. Passo Fundo: UPF, 2003, pp. 41-56.

QUINO. Toda Mafalda. São Paulo: Martins Fontes, 2010.

RODRIGUES, Elizete; SOUZA, Vanderlei de; SOUZA; Marlene de Almeida Augusto de. $\mathrm{O}$ poder atômico do miniconto: análise de narrativas ultracurtas divulgadas em concursos literários na Internet. Revista Letras Raras, v. 2, n. 1, pp. 73-92, 2013. Disponível em: http://revistas.ufcg.edu.br/ch/index.php/ RLR/article/viewFile/144/131 Acesso em: 20 nov. 2017.

SANTOS, Tânia Andrade de Oliveira. Minicontos multimodais a partir de tiras da Turma da Mônica. 2015. Dissertação (Mestrado em Letras). Universidade Federal de Sergipe, São Cristóvão, 2015. Disponível em: http://bdtd.ibict.br/vufind/Record/UFS_8eeb db7c5d045434c3861ff5521b1910 Acesso em: 20 nov. 2017.

TEIXEIRA, Lucia; FARIA, Karla; SOUSA, Silvia Maria de. Textos multimodais na aula de português: metodologia de leitura. Desenredo, v. 10, n. 2, p. 314-336, jul./dez. 2014. Disponível em: http://seer.upf.br/index. $\mathrm{php} / \mathrm{rd} /$ article/view/4295 . Acesso em: 12 ago. 2017. 